\title{
HORMONAL ADAPTATIONS TO DIFFERENT TRAINING INTENSITIES DURING THE PREPARATION OF ELITE JUDOKAS FOR COMPETITION
}

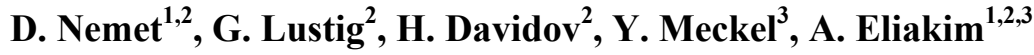 \\ ${ }^{1}$ Child Health \& Sport Center, Pediatric Department, Meir General \\ Hospital, Sackler School of Medicine, Tel-Aviv University, Israel \\ ${ }^{2}$ The Israeli Unit for Sport Excellence, \\ Israeli Olympic Committee, Wingate Institute, Netanya, Israel \\ ${ }^{3}$ Zinman College of Physical Education, \\ Wingate Institute, Netanya, Israel
}

\begin{abstract}
Many efforts are made to quantify objectively the balance between training load and the athlete's tolerance. The aim of the present study was to evaluate the balance between anabolic (i.e. testosterone and IGF-I) and catabolic (i.e. cortisol) hormones in elite judokas during their preparations (4 months) for the European championships. Five healthy elite Israeli judokas (four male, one female, age range 17-26 years) were tested at baseline, after two months of moderate training, after another one month of intense training, after one month of tapering down prior to the competition, and during the week after the championships. Hormonal level remained relatively unchanged during period of moderate training. Circulating levels of IGF-I and testosterone decreased and the cortisol/testosterone ratio increased during intense training. However, only the decrease in circulating IGF-I level reached statistical significance. Both levels of IGF-I and testosterone increased significantly, and the cortisol/testosterone ratio decreased significantly following tapering down, prior to the championships, compared to the levels during intense training. Changes in the balance of anabolic and catabolic hormones during the training season may
\end{abstract}


help elite athletes and assist their coaches in their preparation for the competition.

Key words: athletes, anabolic, catabolic, IGF-I, Judo

\section{INTRODUCTION}

Training efficiency depends on the intensity, volume, duration, and frequency of training and on the athlete's ability to tolerate it. An imbalance between the training load and the individual's tolerance may lead to under or over-training. As a consequence, many efforts are made to quantify objectively the fine balance between training load and the athlete's tolerance. The endocrine system, by modulation of anabolic and catabolic processes, plays a major role in the physiological adaptation to exercise training [23]. For example, the change in the cortisol/testosterone ratio, as an indicator of the anabolic-catabolic balance, has been used with limited success to determine the physiological strain of training $[8,13]$. In addition, changes in circulating components of the growth hormone $(\mathrm{GH}) \rightarrow$ IGF-I (insulin-like growth factor-I) axis, a system of growth mediators that control somatic and tissue growth in many species [15], have been also used to quantify the effects of training [5].

Interestingly, very few studies examined the levels of these anabolic/catabolic hormones in elite athletes, during different training stages throughout the competitive season, in "a real life" condition. Therefore, the aim of the present study was to evaluate the balance between anabolic (i.e. testosterone and IGF-I) and catabolic (i.e. cortisol) hormones in elite judokas during their preparations for the European championships.

\section{SUBJECTS AND METHODS}

Five healthy elite Israeli judokas (four male, one female, age range 17-26 years) participated in the study. All the participants were members of the Israeli national judo team and prepared for the European championships. During the four months follow-up, there were differences in the training intensity. During the first two month 
training intensity was moderate and consisted of 14-16 hours of training per week (35\% weights, $10 \%$ aerobic exercise, $35 \%$ judo fights and $20 \%$ judo techniques and tactics). This period was followed by one month of heavy and intense training (14-16 hours per week, $35 \%$ weight, $0 \%$ aerobic exercise, $50 \%$ judo fights and $15 \%$ judo techniques and tactics). Following the intense training the judokas experienced one month of tapering down prior to the competition. This period was characterized by reduced training volume and increase pure judo practices and tactics, and increased resting periods within each practice (12-14 hours per week, 30\% weight, 10\% aerobic exercise, $30 \%$ judo fights and 30\% judo techniques and tactics). During this period and in particularly in the last week of this period the judokas tried deliberately to reduce their body weight in order to achieve their competition weight category.

Blood Sampling and analysis: Blood samples were collected at baseline (beginning of the season), and at the end of each training period [end of moderate training, end of intense training, end of tapering (two-three days before the competition) and during the week after the competition]. The tests were performed in the morning, following an overnight fast. Blood samples were immediately spun at $3000 \mathrm{rpm}$, at $4^{\circ} \mathrm{C}$ for 20 minutes. The serum was separated and stored at $-80^{\circ} \mathrm{C}$. All specimens were analyzed in the same batch by an experienced technician who was blinded to the order of samples.

Insulin-like Growth Factor-I: IGF-I was extracted from IGFbinding proteins (IGFBPs) by using the acid-ethanol extraction method. Serum IGF-I concentrations were determined by a two-site immunoradiometric assay by using the DSL-5600 Active kit (Diagnostic System Laboratories, Webster, TX). IGF-I intra-assay CV was $1.5-3.4 \%$, and the inter-assay $\mathrm{CV}$ was $3.7-8.2 \%$. Assay sensitivity was $0.8 \mathrm{ng} / \mathrm{ml}$.

Cortisol: Serum cortisol levels were determined by a commercial RIA (Diagnostic Products Corporation, Los Angeles, CA). The intra and inter assay $\mathrm{CV}$ for this assay were $3.2 \%$ and $6.8 \%$ respectively.

Testosterone: Testosterone serum concentrations were determined by ELISA with the use of the DSL commercial kit (Diagnostic System Laboratories, Webster, TX). Intra-assay CV was 4.8-5.3\%, inter-assay $\mathrm{CV}$ was $2.8-4.9 \%$, and the sensitivity was $0.04 \mathrm{ng} / \mathrm{ml}$. 


\section{STATISTICAL ANALYSES}

Repeated measure ANOVA was used to assess the effect of exercise on IGF-I, testosterone and cortisol with time serving as the within group factor. Data are presented as mean \pm SEM. Significance was taken at $\mathrm{p} \leq 0.05$.

\section{RESULTS}

The circulating levels of IGF-I, testosterone, cortisol and the cortisol/ testosterone ratio of the elite judokas at baseline, during periods of moderate and intense training, during tapering prior to the competition and after the competition are summarized in Table 1 and Figure 1. Three of the participants lost in the qualifying rounds of the championships. One judoka finished fifth and one judoka won the European championships. Body weight of the judokas remained stable throughout the training periods with a significant decrease of $2.4 \pm$ $0.3 \mathrm{~kg}(\mathrm{p}<0.01)$ prior to the competition.

Hormonal level remained relatively unchanged during period of moderate training. Circulating levels of IGF-I and testosterone decreased and the cortisol/testosterone ratio increased during intense training. However only the decrease in circulating IGF-I level reached statistical significance. Both levels of IGF-I and testosterone increased significantly, and the cortisol/testosterone ratio decreased significantly prior to the championships compared to the levels during intense training. There was no significant change in cortisol levels during training, but, rather surprisingly, cortisol levels were significantly reduced after the competition. 

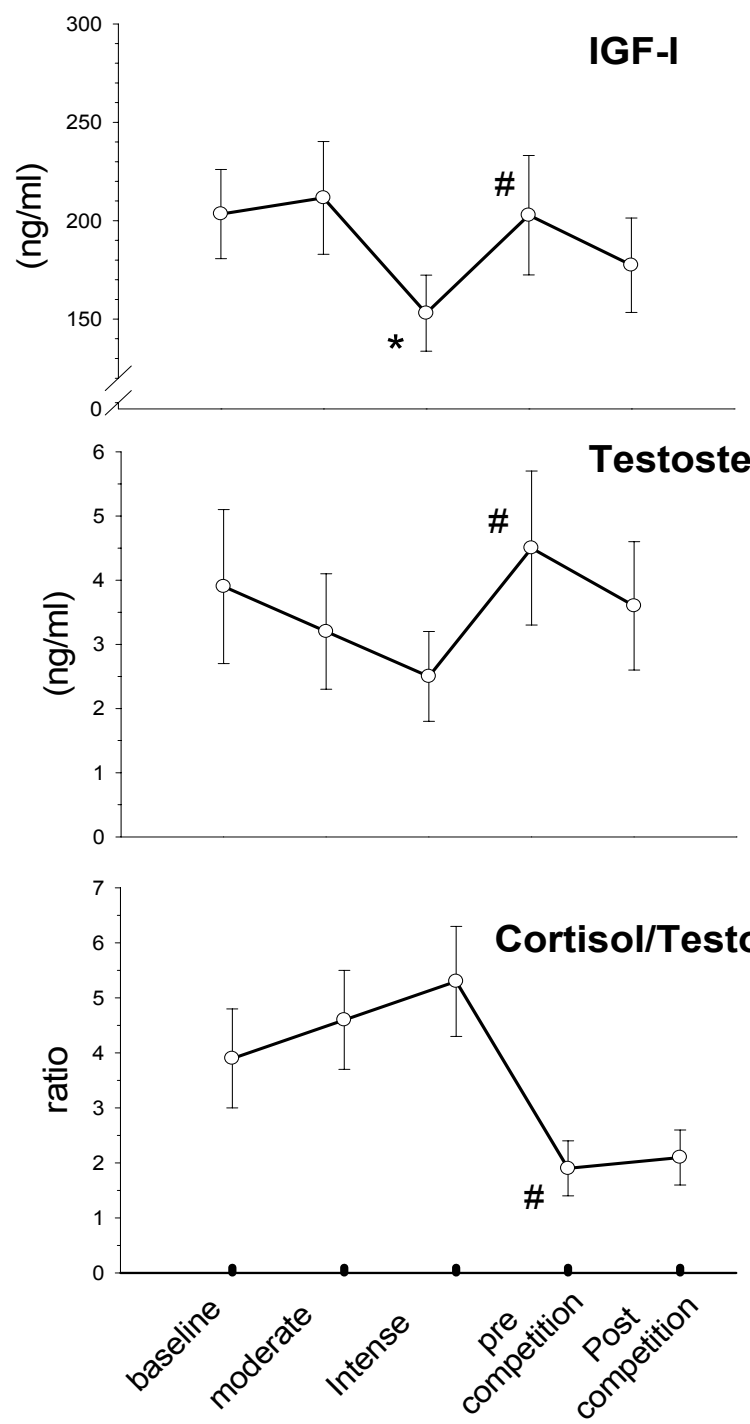

Figure 1. The anabolic/catabolic hormonal profile of elite judokas following different training intensities during the training season. $* \mathrm{p}<0.05$ compared to baseline. ${ }^{\#} \mathrm{p}<0.05$ compared to intense training. 
Table 1. The anabolic/catabolic hormonal profile of elite judokas during the training season.

\begin{tabular}{|l|c|c|c|c|c|}
\hline & Baseline & Moderate & Intense & $\begin{array}{c}\text { Pre } \\
\text { competition }\end{array}$ & $\begin{array}{c}\text { Post } \\
\text { competition }\end{array}$ \\
\hline $\begin{array}{l}\text { IGF-I } \\
(\mathrm{ng} / \mathrm{ml})\end{array}$ & $203.4 \pm 22.7$ & $211.6 \pm 28.6$ & $153.0 \pm 19.3^{*}$ & $202.8 \pm 30.3^{\#}$ & $177.4 \pm 24.0$ \\
\hline $\begin{array}{l}\text { Testoste- } \\
\text { rone } \\
(\mathrm{ng} / \mathrm{ml})\end{array}$ & $3.9 \pm 1.2$ & $3.2 \pm 0.9$ & $2.5 \pm 0.7$ & $4.5 \pm 1.2^{\#}$ & $3.6 \pm 1.0$ \\
\hline $\begin{array}{l}\text { Cortisol } \\
(\mathrm{mcg} / \mathrm{L})\end{array}$ & $17.7 \pm 1.4$ & $18.9 \pm 2.6$ & $16.6 \pm 2.1$ & $11.3 \pm 2.3$ & $9.6 \pm 1.9^{* *}$ \\
\hline $\begin{array}{l}\text { Cortisol/ } \\
\text { Testoste- } \\
\text { rone ratio }\end{array}$ & $3.9 \pm 0 / 9$ & $4.6 \pm 0.9$ & $5.3 \pm 1.0$ & $1.9 \pm 0.5^{\#}$ & $2.1 \pm 0.5$ \\
\hline
\end{tabular}

* $\mathrm{p}<0.05$ intense versus baseline

\# $\mathrm{p}<0.05$ pre competition versus intense training

** $\mathrm{p}<0.05$ post competition versus baseline

\section{DISCUSSION}

We determined the effect of four months of training on circulating IGF-I, testosterone and cortisol level in elite judokas during their preparation for the European championships. Training consisted of two months of moderate training, followed by one month of intense training, and than one month of relative tapering prior to the championships. Both circulating IGF-I and testosterone level decreased during the period of intense training, but only the decrease in IGFI reached statistical significance. Levels of IGF-I and testosterone increased significantly and returned to baseline levels (in the case of testosterone even slightly above baseline levels) during tapering.

We previously demonstrated that the initial response to 5 weeks of endurance-type exercise training was associated with a decrease in circulating IGF-I. These adjustments occurred despite training-induced increases in muscle mass, and improvement in fitness [6-8], suggesting different local tissue, and systemic responses to training. Moreover, these changes occurred even without evidence for negative energy balance or weight loss [19], and were associated with increases in inflammatory mediators [20]. These observations led to the speculation that the sudden imposition of endurance training program first 
leads to hormonal adaptations suggestive of a catabolic state, but at some point, an anabolic rebound occurs. Consistent with this hypothesis, longer periods of training (5m [12], and one year [24]) were indeed associated with increases in circulating GH and IGF-I levels.

Measurements of IGF-I levels can also assist the athlete and coach in the preparation for competition. We previously determined [4] the effect of four weeks of training on fitness, self-assessment physical conditioning scores and circulating IGF-I in elite professional handball players during their preparation for the junior world championships. Training consisted of two weeks of intense training followed by two weeks of relative tapering. Circulating IGF-I and physical conditioning scores decreased initially, and returned to baseline levels at the end of training. There was a significant positive correlation between the changes in circulating IGF-I and the physical conditioning scores. Consistent with our findings, a follow-up of IGF-I levels during the training season in elite adolescent wrestlers showed also a decrease in IGF-I level during periods of heavy training, and return to baseline during tapering down [21].

Hormonal changes during period of intense training are not unique only for IGF-I levels, and may occur in other anabolic hormones, such as testosterone [16, 22] and free testosterone [17], as well. The decreases in testosterone levels can occur following intense endurance and resistance training, and in particularly when training is associated with food restriction and negative energy balance (e.g. in judokas [1]).

Tapering down the training intensity prior to the competition is a well-known training methodology to help the athlete to achieve his best performance [22]. The results of the present study demonstrated that this strategy is indeed associated with parallel increases in both IGF-I and testosterone and with a decrease in the cortisol/testosterone ratio. Therefore, these measures may assist coaches and athletes in their training preparations. Interestingly, in type of sports that do not plan their training for a specific target, and train in the relative same intensity throughout the season (e.g. soccer), changes in IGF-I level were not found [19].

In optimal conditions, during the tapering of training intensity, IGF-I and testosterone level will increase above baseline levels and will be associated with improved performance. This did not occur in the present study. Since both IGF-I and testosterone can be affected by weight loss, it is possible that the deliberate decrease in body weight of the judokas prior to the championships prevented further increase in 
these anabolic hormones, and was associated "only" with a significant return to baseline values. Moreover, previous studies demonstrated training-associated negative correlation between circulating IGF-I and ghrelin in athletes [10], suggesting that these hormonal relationships can play a role in training-induced changes in body composition, in particularly in weight category sports.

As noted earlier, despite the decrease in circulating IGF-I [2, 3, 4, 6,] and testosterone [14] during intense training, fitness may still improve. This suggests that while changes in circulating IGF-I and testosterone are good markers of the general condition and energy balance of the athlete, they are not necessarily good predictors of the athlete's performance. Probably, it is the local muscle levels of these hormones, and their autocrine/paracrine secretion, that is more indicative of the muscle performance $[7,25]$. Tapering of the training intensity, however, was found to be associated with increased IGF-I and testosterone level and with improvement of exercise performance of the athletes $[9,22]$.

It is still unknown what should be the permitted decrease of IGF-I and/or testosterone during periods of heavy training, or what should be the optimal increase of these substances during periods of tapering down and reduced training intensity. However, we believe that an inability to increase circulating IGF-I and/or testosterone levels before the target competition, should be an alarming sign for both the athlete and his/her coach that the athlete's general condition is not optimal. Collection of baseline and training- related hormonal changes, with a comparison to the hormonal response in previous seasons, and the knowledge and experience of the past success may prove to be of a very significant relevance as well.

The cortisol/testosterone ratio has been used frequently as an indicator of the anabolic-catabolic balance. In the present study there was a significant decrease in this ratio along with increase in IGF-I and testosterone during tapering prior to the competition. The changes in this ratio were mainly due to the changes in testosterone since, as was seen previously (e.g. 25), there were no significant changes in cortisol during the training. In addition, cortisol levels were probably more affected by the overall stress and not by training intensity, as suggested by the significantly lower levels after the European championships.

In summary, changes in the balance of anabolic and catabolic hormones during the training season may help elite athletes and their 
coaches in their preparation for the competition. Further studies are needed, however, to clarify the optimal hormonal response and its relationship with the athlete's performance.

\section{REFERENCES}

1. Degoutte F., Jouanel P., Begue R. J., Colombier M., Lac G., Pequignot J. M., Filaire E. (2006) Food restriction, performance, biochemical, psychological and endocrine changes in judo athletes. Int. J. Sport. Med. 27: 9-18.

2. Eliakim A., Brasel J. A., Mohan S., Barstow T. J., Berman N., Cooper D. M. (1996) Physical fitness, endurance training, and the GH-IGF-I system in adolescent females. J. Clin. Endocrinol. Metab. 81: 39863992.

3. Eliakim A., Brasel J. A., Mohan S., Wong W. L. T., Cooper D. M. (1998) Increased physical activity and the growth hormone-IGF-I axis in adolescent males. Am. J. Physiol. 275: R308-R314.

4. Eliakim A., Nemet D., Bar-Sela S., Higer Y., Falk B. (2002) Changes in circulating IGF-I and their correlation with self-assessment and fitness among elite athletes. Int. J. Sport. Med. 23: 600-603.

5. Eliakim A., Nemet D., Cooper D. M. (2005) Exercise, training and the GH $\rightarrow$ IGF-I axis. In: The endocrine system in sports and exercise. W. J. Kraemer, A. D. Rogol (eds). Oxford, UK: Blackwell publishing. 165-179.

6. Eliakim A., Scheett T. P., Newcomb R., Mohan S., Cooper D. M. (2001) Fitness, training, and the growth hormone-insulin-like growth factor-I axis in prepubertal girls. J. Clin. Endocrinol. Metab. 86: 2797-2802.

7. Greig C. A., Hameed M., Young A., Goldspink G., Noble B. (2006) Skeletal muscle IGF-I isoform expression in healthy women after isometric exercise. Growth. Horm. IGF. Res. 16: 373-376.

8. Hoffman J. R., Falk B., Radom Isaac S., Weinstein Y., Magazanik A., Wang Y., Yarom Y. (1997) The effect of environmental temperature on testosterone and cortisol responses to high intensity, intermittent exercise in humans. Eur. J. Appl. Physiol. 75: 83-87.

9. Izquerdo M., Ibanez J., Gonzalez-Badillo J. J., Ratamess N. A., Kraemer W. J., Hakkinen K., Bonnabau H., Granados C., French D. N., Gorostiaga E. M. (2007) Detraining and tapering effects on hormonal responses and strength performance. 21: 768-775. 
10. Jürimäe J., Cicchella A., Jürimäe T., Lätt E., Haljaste K., Purge P., Hamra J., von Duvillard S. P. (2007) Regular physical activity influences plasma ghrelin consentrations in adolescent girls. Med. Sci. Sport. Exer. 39: 1736-1741.

11. Jürimäe J., Jürimäe T., Purge P. (2001) Plasma testosterone and cortisol responses to prolonged sculling in male competitive rowers. J. Sport Sci. 19: 893-898.

12. Koziris L. P., Hickson R. C., Chatterton R. T., Groseth R. T., Christie J. M., Goldflies D. G., Unterman T. G. (1999) Serum levels of total and free IGF-I and IGFBP-3 are increased and maintained in long term training. J. Appl. Physiol. 86: 1436-1442.

13. Kuoppasalmi K., Adlercreutz H. (1984) Interaction between catabolic and anabolic steroid hormones in muscular exercise. In: Exercise Endocrinology, K. Fotherby, S. B. Pal (eds). Berlin: de Gruyter. 6598.

14. Kvorning T., Andersen M., Brixen K., Schjerling P., Suetta C., Madsen K. (2007) Supression of testosterone does not blunt mRNA expression of myoD, myogenin, IGF, myostatin or androgen receptor post strength training in humans. J. Physiol. 15: 579-593.

15. LeRoith D. (1991) Insulin-like growth factores: molecular and cellular aspects. CRC, Boca Raton, FL. 1-54.

16. Lucia A., Diaz B., Hoyos J., Fernandez C., Villa G., Bandres F., Chicharro J. L. (2001) Hormone level of world class cyclists during the tour de Spain stage race. Br. J. Sport. Med. 35: 424-430.

17. Mäestu J., Jürimäe J., Jürimäe T. (2005) Hormonal response to maximal rowing before and after increase in training volume in highly trained male rowers. J. Sport. Med. Phys. Fit. 45: 121-126.

18. Mejri S., Bchir F., Ben Rayana M.C., Ben Hamida J., Ben Slama C. (2005) Effect of training on GH and IGF-I responses to a submaximal exercise in football players. Eur. J. Appl. Physiol. 95: 496503.

19. Nemet D., Connolly P. H., Pontello-Pescatello A. M., Rose-Gottron C., Larson J. K., Galassetti P., Cooper D. M. (2004) Negative energy balance plays a major role in the IGF-I response to exercise training. J. Appl. Physiol. 96: 276-282.

20. Nemet D., Oh Y., Kim H. S., Hill M., Cooper D. M. (2002) Effect of intense exercise on inflammatory cytokines and growth mediators in adolescent boys. Pediatrics 110: 681-689.

21. Nemet D., Pontello A. M., Rose-Gottron C., Cooper D. M. (2004) Cytokines and growth factors during and after a wrestling season in adolescent boys. Med. Sci. Sports. Exerc. 36: 794-800. 
22. Steinacker J. M., Lormes W., Kellman M., Liu Y., Reissnecker S., Opitz-Gress A., Baller B., Gunther K., Petersen K. G., Kallus K. W., Lehmann M., Altenburg B. (2000) Training of junior rowers before world championships. Effects on performance, mood state and selected hormonal and metabolic responses. J. Sport. Med. Phys. Fit. 40: 327-335.

23. Urhausen A., Kindermann W. (2000) The endocrine system in overtraining. In: Sports Endocrinology, M. P. Warren, N. W. Constantini (eds). Totowa NJ: Humana Press. 347-370.

24. Weltman A., Weltman J. Y., Schurrer R., Evans W. S., Veldhuis J. D., Rogol A. D. (1992) Endurance training amplifies the pulsatile release of growth hormone: effects of training intensity. J. Appl. Physiol. 72: 2188-2196.

25. Zanconato S., Moromisato D. Y., Moromisato M. Y., Woods J., Brasel J. A., LeRoith D., Cooper D. M. (1994) Effects of training and growth hormone suppression on insulin-like growth factor-I mRNA in young rats. J. Appl. Physiol. 76: 2204-2209.

\section{Correspondence to:}

Alon Eliakim

Child Health \& Sports Center

Pediatric Department

Meir Medical Center

Kfar-Saba

Israel 